\title{
Echocardiographic identification of aorta and main pulmonary artery in complete transposition ${ }^{1}$
}

\author{
A. B. HOUSTON, N. L. GREGORY, AND E. N. COLEMAN \\ From the Department of Cardiology and University Department of Child Health, Royal Hospital for \\ Sick Children, and the Department of Clinical Physics and Bio-engineering, Glasgow
}

SUMMARY No completely reliable echocardiographic technique has been described for the separate identification of the aorta and main pulmonary artery in complete transposition of the great arteries. A mechanical wide-angle $\left(60^{\circ}\right)$ sector scanner has been applied to this problem in 17 infants and young children, including 8 newborns before angiocardiography. In all patients a longitudinal scan (saggital section) identified the main pulmonary artery by its directly posterior course immediately beyond the pulmonary valve, and the aorta by its retrosternal course upwards before turning posteriorly above the main pulmonary artery. In addition, a high transverse scan showed the precise spatial relation of the great arteries, and, in 11 of the 17, tilting the scanning plane upwards showed branching of the main pulmonary artery. In 8 infants examined with $M$-mode echocardiography, an upward sweep from the pulmonary valve showed abrupt termination of the echo from the posterior wall coinciding with the posterior arching of the main pulmonary artery.

The echocardiographic diagnosis of complete transposition of the great arteries has been based largely upon the demonstration of an abnormal relation of the semilunar valves (Dillon et al., 1973; Gramiak et al., 1973) or of the great artery origins (King et al., 1973; Sahn et al., 1974; Henry et al., 1975; Maron et al., 1975). However, the relation of the great arteries can vary considerably in the rarer transposition complexes (Van Praagh et al., 1971) and in other forms of complicated congenital heart disease. Therefore, for an accurate assessment of great artery anatomy it is essential that the aorta and pulmonary artery should be separately identified.

We report on the use of a mechanical $60^{\circ}$ sector scanner to identify the aorta and pulmonary artery in infants with complete transposition of the great arteries and, arising from our findings, a preliminary study of $\mathrm{M}$-mode echocardiography in making this distinction.

\section{Methods}

Studies were made on 18 infants with normally related great arteries: 9 were less than 10 days old

\footnotetext{
${ }^{1}$ Supported in part by a research grant from the Equipment Research Committee of the Chief Scientist's Organisation of the Scottish Home and Health Department.
}

Received for publication 13 September 1977 and 9 were between 1 month and 1 year. Their weights ranged from $2 \cdot 2 \mathrm{~kg}$ to $10.3 \mathrm{~kg}$. All were examined with two-dimensional echocardiography and in all 9 of the newborns and in 6 older infants an $M$-mode recording was made as a sweep from the anterior mitral leaflet to the aortic valve was continued upwards to follow the ascending aorta as far headwards as possible. In addition, 17 infants and children with complete transposition of the great arteries were studied; the examination was carried out before cardiac catheterisation and angiocardiography in 8 newborn infants less than 14 days old, and after angiocardiography in 9 children between 2 weeks and 20 months old. Their weights ranged from $2.7 \mathrm{~kg}$ to $8.7 \mathrm{~kg}$. Examination with $\mathrm{M}$-mode echocardiography was carried out after angiocardiography on 7 of these, whose ages ranged from 8 days to 20 months, and before two-dimensional echocardiography or angiocardiography on one 2-day-old baby.

The real-time two-dimensional scanning equipment was a hand-held mechanical $60^{\circ}$ sector scanner fitted with a $5 \mathrm{MHz} 6 \mathrm{~mm}$ transducer focused for optimum performance in the range 20 to $40 \mathrm{~mm}$ (Shaw et al., 1976; Houston et al., 1977b). The oscillating transducer is ultrasonically coupled to the patient through an oil-filled cell which, while separating the patient from the movement of the transducer, maintains ultrasonic contact and avoids 
discomfort. The scanner and interface unit were used in conjunction with a Nuclear Enterprise Diasonograph (NE 4200) fitted with a cardiac module. The $\mathrm{M}$-mode recordings were obtained on a fibreoptic recorder (NE 4105) after stopping the transducer in an appropriate position or with a separate hand-held transducer.

The two-dimensional scanning planes employed were longitudinal and high transverse; the technique for obtaining these has been described elsewhere (Houston et al., 1977b). A longitudinal view was obtained through the left ventricle to include the ventricular septum, the mitral valve, and the semilunar valve continuous with it; the scanner was then tilted or moved superiorly to show the supravalvar part of the great artery arising from the left ventricle. A high transverse view was then obtained and adjusted to show either the normal crescentic right ventricular outflow and main pulmonary artery crossing the aorta, or the two circular spaces with central cusp echoes in diastole characteristic of the parallel great arteries in complete transposition of the great arteries. In the patients with complete transposition of the great arteries the scanning plane was at this point tilted towards the head in an attempt to show branching of the pulmonary artery (Houston et al., 1977a). The plane was then adjusted to provide a longitudinal view of the supravalvar aorta. Still frames of the transverse view from patients with complete transposition of the great arteries were used to assess the relation of the great arteries and to compare their diameters at valve level.

M-mode echocardiograms of the supravalvar portion of the great artery arising from the left ventricle were obtained by continuing a conventional sweep from the mitral to the semilunar valve upwards to follow the great artery as far headwards as possible.

\section{Results}

\section{TWO-DIMENSIONAL ECHOCARDIOGRAPHY}

\section{Normally related great arteries}

In the infants with normally related great arteries, the longitudinal view showed that the aorta followed a long course upwards approximately parallel to the sternum (Fig. 1). The transverse view showed the aorta in cross-section with the right ventricular outflow crossing in front of it and the main pulmonary artery to its left (Fig. 2).

\section{Complete transposition of the great arteries}

In all 17 patients with complete transposition of the great arteries the longitudinal view showed the

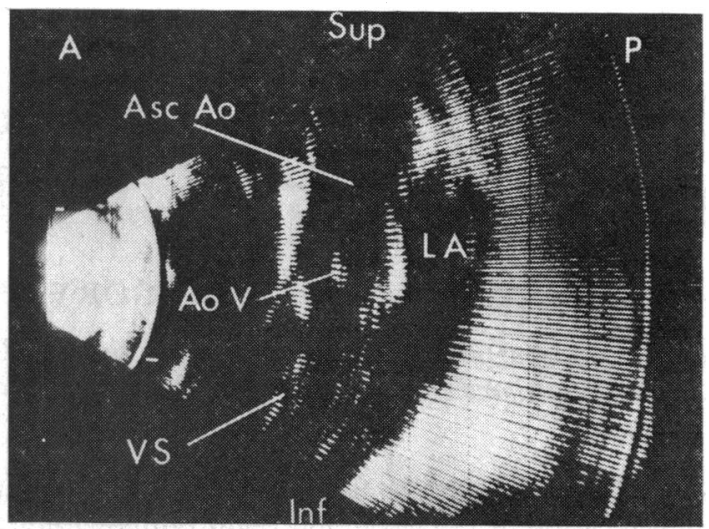

Fig. 1 Electrocardiogram-triggered diastolic

longitudinal view from a $2 \cdot 8 \mathrm{~kg}$ infant with normally related great arteries, showing the ascending aorta. The marker arcs are $5 \mathrm{~cm}$ apart. $A$, anterior; $P$, posterior; Sup, superior; Inf, inferior; Asc Ao, ascending aorta; $L A$, left atrium; AoV, aortic valve cusps; $V S$, ventricular septum.

artery arising from the left ventricle to turn posteriorly almost immediately beyond the valve (Fig. 3), thus allowing its identification as the main pulmonary artery.

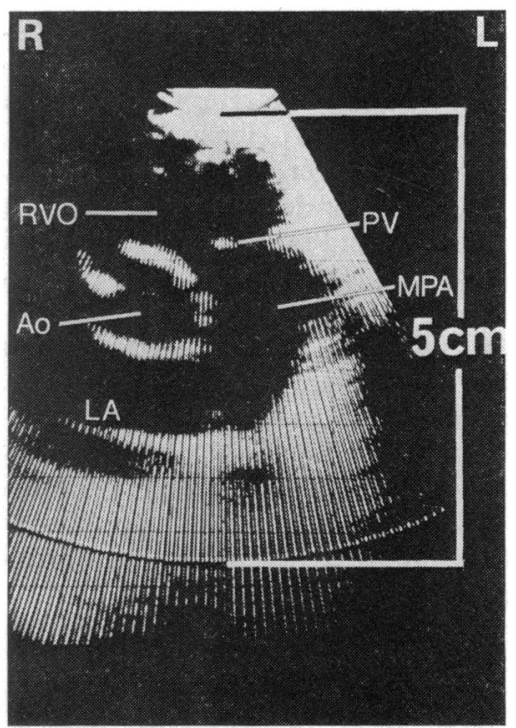

Fig. 2 Electrocardiogram-triggered diastolic transverse view from the infant in Fig. 1. The right ventricular outflow crosses anteriorly to the aortic root (shown in cross section) and turns posteriorly as the main pulmonary artery. $R$, right; $L$, left; $R V O$, right ventricular outflow; PV, pulmonary valve cusps; MPA, main pulmonary artery; Ao, aorta; $L A$, left atrium. 




Fig. 3 Video-recorded longitudinal view from 13-day-old infant with complete transposition of the great arteries. The main pulmonary artery rises from the left ventricle and turns posteriorly immediately above the valve cusps. Abbreviations as in Fig. 1 and 2.

The other great artery, arising from the right ventricle, was seen to have a longer upward course confirming that this was the aorta (Fig. 4). Both great arteries could be clearly shown in a single longitudinal view only in those patients with anterior-posterior great arteries. Transverse views in all patients showed the origins of the great arteries as two circles with central cusp echoes in diastole. The relation of the arteries determined from this view corresponded with that found at angiocardiography; in 13 the aorta was anterior and to the right

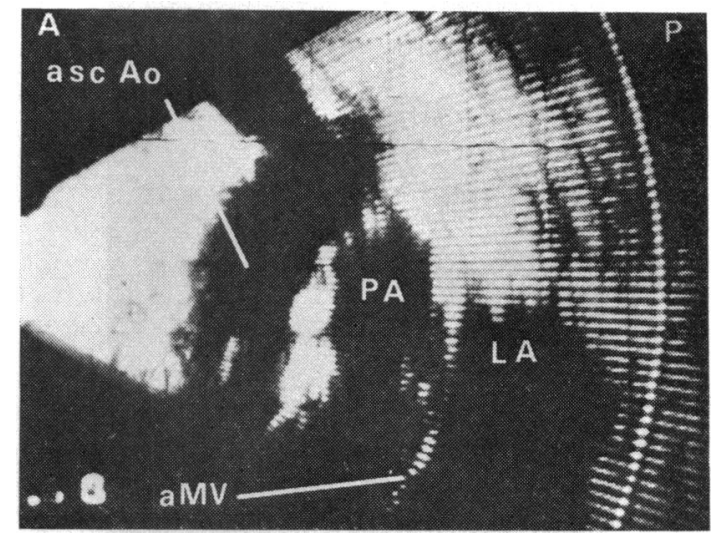

Fig. 4 Video-recorded longitudinal view from a 10-day-old infant with complete transposition of the great arteries. The anterior aorta turns posteriorly above the main pulmonary artery which is sectioned obliquely. The relations of the great arterial roots are shown in Fig. 5a. PA, main pulmonary artery; aMV, anterior mitral valve leaflet; other abbreviations as in Fig. 1.

of the main pulmonary artery (Fig. 5a), in 3 directly anterior (Fig. 5b), and in 1 side-by-side to the right (Fig. 5c). In 11 patients branching of the main pulmonary artery (Fig. 6) was shown by tilting or edging the scanning plane upwards. Comparison of the diameters of the arteries at valve level showed that in 4 the great arteries were of the same size, that in 9 the pulmonary artery was larger than the aorta, and that in 4 it was smaller.

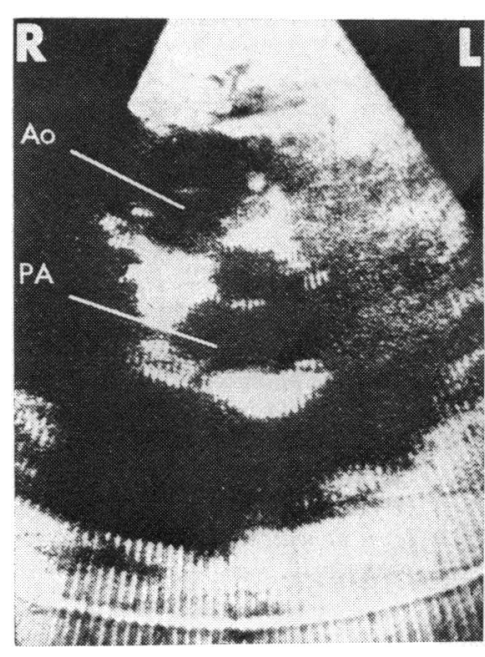

(a)

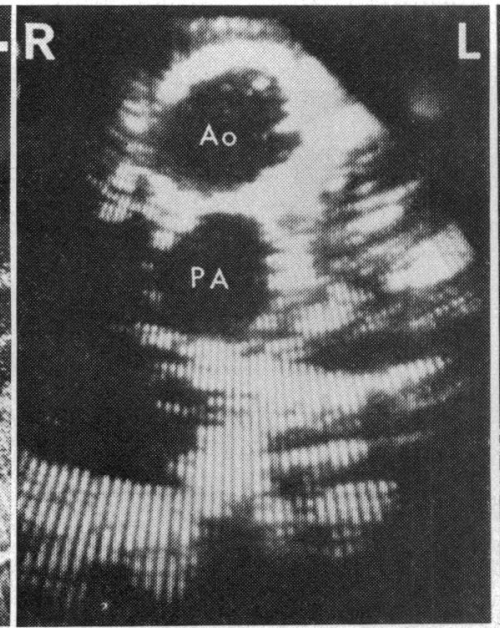

(b)

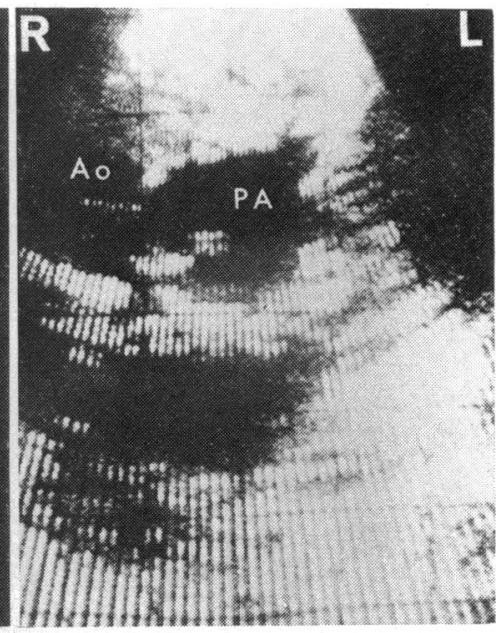

(c)

Fig. 5 Video-recorded high transverse views in complete transposition of the great arteries from infants aged 10 days, 11 months, and 13 days, respectively. (a) The aorta lies anterior and to the right of the main pulmonary artery; (b) the aorta lies directly anterior to the main pulmonary artery; and (c) the great arteries lie side by side. Abbreviations as in Fig. 2 and 4. 


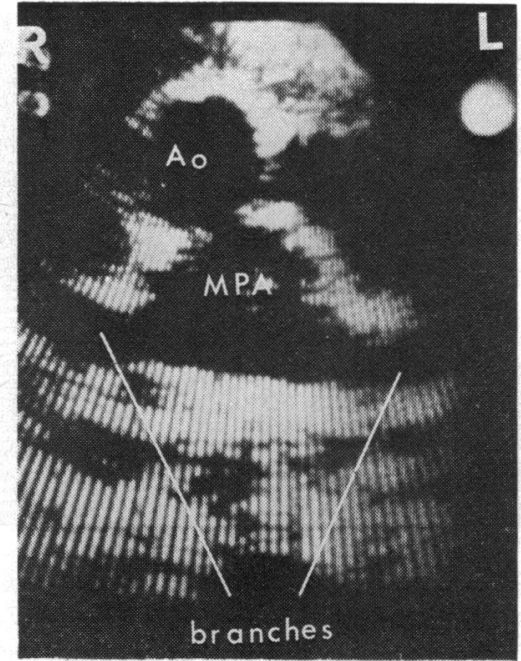

Fig. 6 Video-recorded high transverse view from the infant in Fig. 5b, with the scanning plane tilted upwards from position in Fig. $5 b$ to show branching of the pulmonary artery. Abbreviations as in Fig. 2.

\section{M-MODE ECHOCARDIOGRAPHY}

The $M$-mode sweep upwards from the aortic valve in the 15 normal subjects showed the upwards continuation of both the anterior and the posterior walls of the aorta. In the 8 patients with complete transposition of the great arteries in whom an M-mode recording was made, just above the point at which the pulmonary valve cusp echoes disappeared, the linear echo from the posterior wall abruptly termi- nated as it became the posteroinferior wall when the main pulmonary artery turned backwards (Fig. 7).

\section{Discussion}

Complete transposition of the great arteries is the most common form of cyanotic congenital heart disease presenting in the neonatal period (Rowe and Mehrizi, 1968) and immediate diagnosis is essential. In recent years echocardiography has been used as a noninvasive technique for the assessment of the cyanotic newborn infant (Godman et al., 1974) and criteria for the echocardiographic diagnosis of complete transposition of the great arteries have emerged. These have been based largely on the demonstration of an abnormal relation of the semilunar valves with $M$-mode echocardiography (Dillon et al., 1973; Gramiak et al., 1973) or of the origins of the great arteries with electrocardiogram gated Bscanning (King et al., 1973) or real-time twodimensional systems (Sahn et al., 1974; Henry et al., 1975; Maron et al., 1975). These techniques do not identify the great arteries individually but distinguish the aorta (or its valve) by its anterior right position relative to the pulmonary artery. But in 21 per cent of cases of complete transposition of the great arteries this relation does not hold (Nadas and Fyler, 1972). Attempts have been made to distinguish the great arteries with $\mathrm{M}$-mode echocardiography by comparing systolic time intervals (Solinger et al., 1974; Fouron et al., 1976) or the outside diameters of the great artery roots (Solinger et al., 1974) or, most recently, by using contrast echocardiography (Mortera et al., 1977). Measurement

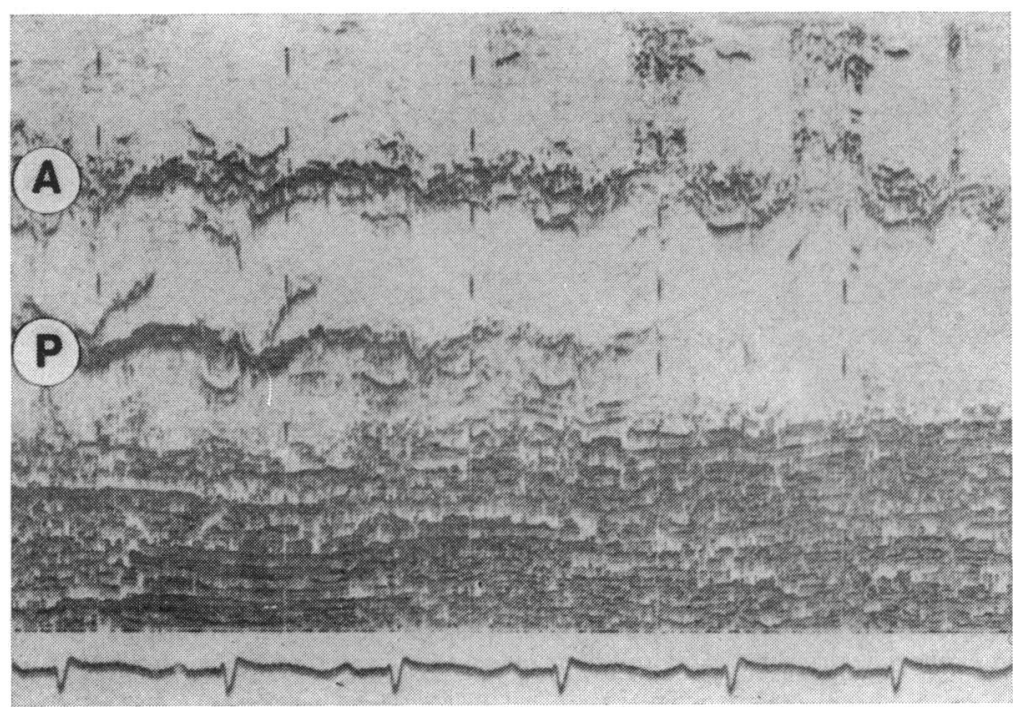

Fig. $7 \quad M$-mode sweep upwards from the pulmonary valve in a 5-month-old infant. The upward continuation of the anterior wall $(A)$ is seen but the posterior wall (P) terminates abruptly at the level at which it turns posteriorly. 
of electromechanical systole, ventricular ejection times, and pre-ejection periods allows the great arteries to be differentiated, but only when the pulmonary vascular resistance is low (Solinger et al., 1974; Fouron et al., 1976). Though the outside diameter of the pulmonary artery root has been reported to be larger than that of the aortic root in normal infants (Solinger et al., 1973; Hagan et al., 1973), this observation is likely to be of little practical value in differentiating the great arteries in complete transposition of the great arteries, where in those with no ventricular septal defect or pulmonary stenosis Shaher (1973) found them to be equal in 54 per cent. Mortera et al. (1977) used contrast echocardiography with injection into a systemic vein and a suprasternal approach to show both great arteries simultaneously with $\mathrm{M}$-mode echocardiography. With this approach the artery nearer the probe is the aorta and in patients with an intact ventricular septum and complete transposition of the great arteries this was shown to opacify more intensely, suggesting that it arose from the right ventricle. This technique was considered to be ineffective when there was a large ventricular septal defect.

Two-dimensional echocardiography, with a transverse scan, can show the parallel great arteries characteristic of the transposition complexes. Furthermore, Sahn et al. (1974) suggested that in a longitudinal scan the long retrosternal course of the aorta might allow it to be recognised, but the pulmonary artery was not positively identified. In some cases the pulmonary artery can be identified by its branching (Houston et al., 1977a) but in almost one-third of our cases this could not be convincingly shown for the purpose of precise diagnosis, and a more universally applicable finding was still required. Using a mechanical sector scanner we have been able to differentiate the aorta from the main pulmonary artery in longitudinal scans in all 17 patients with complete transposition of the great arteries. In accord with the suggestion of Sahn et al. (1974), the long retrosternal course of the aorta has been shown, but this course is subject to variation. To prove that this artery is the aorta it should be shown to turn posteriorly at a level above the main pulmonary artery, which we can now independently identify by its posterior course immediately beyond the pulmonary valve. Thus two-dimensional echocardiography provides a reliable visual recognition of the great arteries in complete transposition of the great arteries. Though this study has included only patients with complete transposition of the great arteries, we believe the method to be applicable to the identification of the great arteries in other complex forms of congenital heart disease. In the new- born infants with complete transposition of the great arteries examined before cardiac catheterisation and angiography, the diagnosis was reached and the anatomy of the proximal great arteries correctly determined by echocardiography. Demonstration of the posterior course of the main pulmonary artery arising from the left ventricle can allow the diagnosis to be made in less than 2 minutes.

The results of the study with two-dimensional echocardiography suggested that it might be possible to recognise the posterior sweep of the main pulmonary artery with $\mathrm{M}$-mode echocardiography. In the 8 patients upward angulation of the transducer from the pulmonary valve did indeed show apparent widening of the vessel, corresponding to the posteriorly directed course of the main pulmonary artery (Fig. 7); this allowed the diagnosis to be reached with $\mathrm{M}$-mode echocardiography in the one newborn infant examined before two-dimensional echocardiography or angiocardiography. We have been unable to elicit a similar appearance by following the aorta upwards in infants with normally related great arteries. We, therefore, suspect that this feature on $M$-mode echocardiography may allow the identification of the main pulmonary artery arising from the left ventricle, though variations in the course of the artery will be more readily appreciated with two-dimensional echocardiography.

We have found that two-dimensional echocardiography provides a fast and reliable method of distinguishing the aorta from the main pulmonary artery and thus of providing a rapid diagnosis of complete transposition of the great arteries.

We thank Mr J. S. Paton, B.Sc., who designed the scanning head, Mr A. Shaw, B.Sc., who directed the development of the scanning equipment, and $\mathbf{M r}$ D. J. Wheatley, F.R.C.S., who initiated its clinical application. We acknowledge the help we have received from Dr E. M. Sweet, Dr M. M. Mair, and Miss J. L. McLardy of the Radiology Department of the Royal Hospital for Sick Children, Glasgow.

\section{References}

Dillon, J. G., Feigenbaum, H., Konecke, L. L., Keutel, J., Hurwitz, R. A., Davis, R. H., and Chang, S. (1973). Echocardiographic manifestations of $d$-transposition of the great vessels. American fournal of Cardiology, 32, 74-78.

Fouron, J. C., Bozio, A., Espelta-Vela, F., Poyot, M., and Davignon, A. (1976). Echocardiographic identification of the great arteries using systolic time intervals in the newborn (abstract). Abstract Book 1, 7th European Congress of Cardiology, p. 776.

Godman, M. J., Tham, P., and Kidd, B. S. L. (1974). Echocardiography in the evaluation of the cyanotic newborn infant. British Heart Fournal, 36, 154-166. 
Gramiak, R., Chung, K. J., Nanda, N., and Manning, J. (1973). Echocardiographic diagnosis of transposition of the great vessels. Radiology, 106, 187-189.

Hagan, A. P., Deely, E. J., Sahn, D., and Friedman, W. F. (1973). Echocardiographic criteria for normal newborn infants. Circulation, 48, 1221-1226.

Henry, W. L., Maron, B. J., Griffith, J. M., Redwood, D. R., and Epstein, S. E. (1975). Differential diagnosis of anomalies of the great arteries by real-time two-dimensional echocardiography. Circulation, 51, 283-291.

Houston, A. B., Gregory, N. L., and Coleman, E. N. (1977a). Two-dimensional sector scanner echocardiography in cyanotic congenital heart disease. British Heart fournal, 39, 1076-1081.

Houston, A. B., Gregory, N. L., Shaw, A., Wheatley, D. J., and Coleman, E. N. (1977b). Two-dimensional echocardiography with a wide angle $\left(60^{\circ}\right)$ sector scanner. British Heart fournal, 39, 1071-1075.

King, D. L., Steeg, C. N., and Ellis, K. (1973). Demonstration of transposition of the great arteries by cardiac ultrasonography. Radiology, 107, 181-186.

Maron, B. J., Henry, W. L., Griffith, J. M., Freedom, R. M. Kelly, D. T., and Epstein, S. E. (1975). Identification of congenital malformations of the great arteries in infants by real-time two-dimensional echocardiography. Circulation, 52, 671-677.

Mortera, C., Hunter, S., and Tynan, M. (1977). Diagnosis of ventriculo-arterial discordance (transposition of the great arteries) by contrast echocardiography. British Heart fournal, 39, 844-846.
Nadas, A. S., and Fyler, D. C. (1972). Paediatric Cardiology, 3rd ed., p. 610. W. B. Saunders, Philadelphia.

Rowe, R. D., and Mehrizi, A. (1968). The Neonate with Congenital Heart Disease, p. 80. W. B. Saunders, Philadelphia.

Sahn, D. J., Terry, R., O'Rourke, R., Leopold, G., and Friedman, W. F. (1974). Multiple crystal cross-sectional echocardiography in the diagnosis of cyanotic congenital heart disease. Circulation, 50, 230-238.

Shaher, R. M. (1973). Complete Transposition of the Great Arteries, p. 135. Academic Press, New York.

Shaw, A., Paton, J. S., Gregory, N. L., and Wheatley, D. J. (1976). A real-time two-dimensional ultrasonic scanner for clinical use. Ultrasonics, 14, 35-40.

Solinger, R., Elbl, F., and Minhas, K. (1973). Echocardiography in the normal neonate. Circulation, 47, 108-118.

Solinger, R., Elbl, F., and Minhas, K. (1974). Deductive echocardiographic analysis in infants with congenital heart disease. Circulation, 50, 1072-1096.

Van Praagh, R., Pérez-Trevino, C., López-Cuellar, M., Baker, F. W., Zuberbuhler, J. R., Quero, M., Pérez, V. M., Moreno, F., and Van Praagh, S. (1971). Transposition of the great arteries with posterior aorta, anterior pulmonary artery, subpulmonary conus and fibrous continuity between aortic and atrioventricular valves. American fournal of Cardiology, 28, 621-631.

Requests for reprints to $\operatorname{Dr} A$. B. Houston, Royal Hospital for Sick Children, Yorkhill, Glasgow G3 8SJ. 